\title{
COMPRENDER Y DESAFIAR LA POLITIZACIÓN DE LAS MIGRACIONES Y LA INTERCULTURALIDAD. RESEÑA DEL LIBRO: SANDOVAL-GARCÍA, C. (ED.) (2020). PUENTES, NO MUROS: CONTRIBUCIONES PARA UNA POLÍTICA PROGRESISTA EN MIGRACIONES. CLACSO
}

Sophia Roldán Soto ${ }^{1}$

ORCID: 0000-0002-4304-7349

Estado de bienestar, redistribución de la riqueza, desarrollo sostenible, derechos humanos; estos son algunos de los factores que caracterizan las políticas progresistas y de los cuales se ha excluido a las personas víctimas de desplazamientos forzados. Carlos Sandoval García aborda esta cuestión en este libro producto del coloquio "La politización de la migración. Desafíos para el pensamiento crítico y la política progresista" publicado en 2017 y que recopila las voces de doce autores y autoras. La obra comprende ocho capítulos, sobre temáticas vinculadas con la securitización de lo migratorio, racialización de la clase, construcción de símbolos e identidades, movimientos políticos, el nativismo y la emancipación en el Sur Global, particularmente, en el contexto centroamericano.

El libro abre con el capítulo "La construcción social de la persona migrante como enemigo", de Mauricio Gaborit. Esta sección explora el miedo a la otredad, la aporofobia, la sensación de inseguridad sobre el sistema democrático receptor de migrantes y el reparto de recursos que se consideran limitados como para compartirlos con "ajenos a nuestra sociedad".

Tales elementos, como lo expone Gaborit, son el caldo de cultivo para la militarización de las fronteras, mediante tres espacios propuestos por David Harvey (2003), (como se cita en Sandoval-García, 2020): el absoluto, -donde se materializan políticas y fenómenos sociales-; el relativo, -que contiene la estructura social y sus flujos;-y el relacional, que comprende -vínculos sociales directos-.

1 Universidad Nacional, Escuela de Relaciones Internacionales, Heredia, Costa Rica. Estudiante de Bachillerato en Relaciones Internacionales. Correo: roldansotouniv@gmail.com 
Así, Gaborit propone que estos tres espacios tan líquidos (inciertos, manipulables) son los que a su vez permiten el planteamiento de retóricas xenofóbicas y la oposición a acciones afirmativas. El desarrollo de los espacios propuestos por Harvey en la argumentación de Gaborit contribuye con la comprensión del origen y consolidación del discurso xenofóbico; aunque, el uso de más datos estadísticos hubiese sido un recurso valioso en el análisis de, por ejemplo, las brechas financieras y sus efectos en las posiciones de aceptación o rechazo respecto a la migración.

El segundo capítulo lleva por nombre "Reflexiones sobre el apartheid global y la migración", escrito por Yajaira Ceciliano-Navarro y Tanya Golash-Boza. Las autoras exploran la condición multidimensional de la discriminación y la xenofobia desde la perspectiva del apartheid como orden mundial.

Similar al capítulo anterior, encuentra correlaciones entre la segregación, el nacionalismo y la atribución de características peyorativas a las personas migrantes: violencia, peligro y enfermedad; todos ellos reproducidos en diferentes regiones del hemisferio norte, mediante recursos como la criminalización y la animalización (aquí se presenta los términos de coyotaje y shetou ${ }^{2}$ como ejemplos). Asimismo, reconoce el reparto desigual de las riquezas globales, el cual privilegia a ciertas minorías blancas por medio de la exclusión y la inestabilidad política generada por políticas económicas neoliberales.

El tercer apartado corresponde a "Las migraciones de Centroamérica y el mito securitario de Occidente: ¿un nuevo-viejo acontecimiento?" escrito por María del Carmen García-Aguilar y Daniel Villafuerte-Solís. Este capítulo describe elementos pertenecientes a la trama mitológica en los alcances de la seguridad en las fronteras, es decir, combinar los procesos de toma de decisión con hechos falsos que se anuncian como verdades en los contextos geopolíticos y fronterizos.

A los ojos de la ciudadanía, estos mitos asignados a la población migrante constituyen un desafío a la institucionalidad en términos de poder duro. Pero, además, erróneamente, se les percibe como una amenaza a la tradición social, al poder blando, que debe ser mitigada a pesar de sus potenciales aportes culturales.

En esta misma línea, el cuarto capítulo, "Documentar a las personas migrantes en México: ¿protegiendo a los vulnerables o disciplinando a los ingobernables?” de Tanya Basok, describe límites en las políticas progresistas. Se responsabiliza

2 Shetou (舌头): cabeza de serpiente en mandarín. Término que se utiliza para referirse a los corredores y los traficantes de la migración. 
a las personas migrantes por su volumen de flujo, el uso que hacen de los servicios públicos y su actuar al compararlos con otras poblaciones en situación de vulnerabilidad.

Basok entonces presenta como caso de estudio la movilización forzada de personas haitianas, así como las condiciones que enfrentaron en cada país de Centroamérica hasta su llegada a México, lo anterior con un doble propósito: mostrar las situaciones de maltrato en los campos establecidos para su estadía temporal y la forma en la que entraron al discurso mexicano para condicionar la documentación y el sometimiento de futuros grupos (en donde particularmente se ven afectados Centroamérica y el Caribe).

El quinto capítulo corresponde a la "Política social y la politización de la migración en América Latina”, de los autores Koen Voorend y Megan Rivers-Moore sobre la interculturalidad y "la incorporación social y económica de las personas migrantes" más allá de los procesos relativos a su estadía y documentación (Sandoval-García, 2020, p.95). Luego de hacer un breve repaso de la situación en naciones como Uruguay, Argentina y Chile, el apartado se concentra en estudiar las reformas legislativas concernientes a la inmigración en Costa Rica.

A diferencia de los anteriores capítulos, Voorend y Rivers-Moore se apropian de información estadística para desmontar los mitos utilizados para estos procesos de politización mencionados. Asimismo, destaca la actitud titubeante de Costa Rica para participar activamente de convenios impulsados por organismos como el SICA, orientados a mejorar la situación de las personas migrantes.

En el sexto capítulo: “¿Por qué la migración se convierte en la bandera de las derechas? Consideraciones para una política progresista”, Carlos Sandoval-García se encarga de responder directamente a las retóricas de dichas corrientes políticas, uniendo el contenido del capítulo con el título del libro.

Sandoval-García desarrolla un argumento que vincula la securitización de los territorios con los cuerpos, dando a entender que las personas (y su condición socioeconómica-cultural) son el principal objetivo de los discursos que movilizan y articulan a las ultraderechas, más que el control por los espacios físicos.

Aunque el autor referencia a politólogos como Fukuyama para valorar el ascenso de la derecha tras la Guerra Fría, hubiese sido interesante abordajes que podrían considerarse menos tradicionales, por ejemplo, emplear propuestas desde de la Geopolítica Feminista; las cuales conceptualizan la "reconquista" de los territorios y el populismo punitivo desde la visión cuerpo-identidad (no solo ideología). 
Entrando al cierre del libro, se encuentra el séptimo capítulo: "Construyendo ciudades solidarias: de la protesta a la política", a cargo de Stefanie Kron y Henrik Lebuhn. En él, buscan contribuir al debate sobre las propuestas progresistas al observar las protecciones que la ciudadanía urbana y las ciudades santuarios proveen a la población inmigrante que no ha conseguido la nacionalidad o se enfrenta a la detención y deportación. Kron y Lebuhn reiteran la importancia de los gobiernos locales como defensores de los derechos sociales globales, mediante estrategias que abarcan la facilitación de los diálogos y la identificación municipal para permitir el acceso a servicios públicos como educación, bibliotecas y pago de alquileres.

El octavo capítulo, el final, recapitula las ideas que han sido expuestas a lo largo del libro. "Desafiando el discurso securitario: la propuesta de las fronteras abiertas", por Juan Carlos Velasco, mismo que enfrenta la construcción de las fronteras como barreras y las posturas socialistas y antirracistas, concluyendo que más que formular políticas que resuelvan la llegada de personas migrantes, debe desmontarse el modelo distributivo contemporáneo que ocasiona su huida desde el Sur Global. A pesar de esta interesante propuesta, sus planteamientos desde la filosofía llegan a ser muy generales y pareciera que estos se podrían ubicar mejor en la sección introductoria de esta obra que en su parte final.

Así, al analizar cada capítulo, es posible determinar su distribución por ejes temáticos: las políticas en el Norte Global, los límites del progresismo en las organizaciones internacionales, el contexto centroamericano y, finalmente, las reflexiones generales sobre la construcción de los símbolos que atañen a la población migrante.

Puentes, no muros: contribuciones para una politica progresista en migraciones aborda la migración desde espacios tan diversos como la sociología, la educación política y los estudios de la cultura; enriqueciendo así el análisis multidisciplinario de este complejo fenómeno. Su leit motiv se encuentra ligado a la inclusión de las personas migrantes no solo desde un reconocimiento político, sino en la cotidianeidad de las bases sociales.

Entre sus principales aportes, se encuentran la presentación de estudios de caso, más en coyunturas micro que sistémicas, para evaluar el éxito y el fracaso de diversas políticas progresistas tales como: el movimiento santuario, la categorización de "emergencia nacional" para la inmigración centroamericana y la participación estadounidense en su historia, documentación y estatus, el papel de las ciudades portuarias en el Norte y el dejar de percibir la securitización de lo migratorio como un fenómeno aislado, constituyéndose esta última en la línea base del libro. 
No obstante lo anterior, un análisis crítico de la obra evidenció la carencia de cuestionamientos sobre métodos coercitivos (más allá del discurso), contra los países de donde provienen estas poblaciones: bloqueos comerciales, proyectos de desarrollo, extractivismo, entre otros. Es decir, manifestaciones de neoimperialismo y de la concentración desigual del poder económico, que debilitan la soberanía y las posibilidades de desarrollo inclusivo en el Sur Global.

A pesar de ello, para la disciplina de las Relaciones Internacionales, este libro representa un creativo abordaje sobre la securitización de lo migratorio, aspecto que bien podría complementarse con los Estudios de la Paz y Desarrollo, así como con aquellas aproximaciones teóricas enfocadas en analizar fenómenos de naturaleza transnacional donde, si bien el Estado es un elemento clave, debe coexistir con actores y fenómenos que rebasan su comprensión tradicional de fronteras y seguridad.

Lo anterior, gracias a la especial atención que presta la obra respecto a los esfuerzos realizados por entidades locales como municipalidades e individuos que, entre otras iniciativas, lideran campañas de comunicación para el desarrollo, enfocadas en preservar la humanidad de la persona migrante y en defender sus Derechos Humanos.

\section{Referencias}

Sandoval-García, C. (Ed.) (2020). Puentes, no muros: contribuciones para una política progresista en migraciones. CLACSO. 
